\title{
Three-dimensional Observation of Nonmetallic Inclusion Clusters in Solid Metal by X-ray Micro-CT
}

\author{
Tao $\mathrm{LI}^{1,2) *}$ Shin-ichi SHIMASAKI, ${ }^{1,3)}$ Shoji TANIGUCHI, ${ }^{1)}$ Shunsuke NARITA ${ }^{1,4)}$ and Kentaro UESUGI ${ }^{5)}$ \\ 1) Graduate School of Environmental Studies, Tohoku University, 6-6-20 Aoba-yama, Aoba-ku, Sendai, 980-8579 Japan. \\ 2) Norwegian University of Science and Technology, Kolbjørn Hejes $\vee 1 B, 7491$, Trondheim, Norway. $\quad 3)$ Department of \\ Electro-Mechanical Systems Engineering, National Institute of Technology, Kagawa College, 335, Chokushi-cho, Takamatsu, \\ 761-8058 Japan. $\quad$ 4) Daido Steel Co. Ltd., 1-10, 1-chome Higashisakura, Higashi-ku, Nagoya, Aichi, $461-8581$ Japan. \\ 5) Japan Synchrotron Radiation Research Institute (JASRI)/ Spring-8, 1-1-1 Kouto, Sayo-cho, Sayo-gun, Hyogo, $679-5198$ Japan.
}

(Received on April 12, 2016; accepted on July 4, 2016)

\begin{abstract}
In this study, we developed a method of observing three-dimensional (3D) inclusion clusters in metal. The theory of X-ray micro-computed tomography $(\mathrm{CT})$ is generally introduced. The criteria on determining the sample size and energy of X-ray beam is set according to the characteristics of the beamline BL20XU available at Spring-8, which is the largest synchrotron radiation facility. The $\mathrm{Al}-\mathrm{TiB}_{2}$ and $\mathrm{Al}-\mathrm{SiC}$ system were measured by the X-ray micro-CT available in beamline BL20XU at Spring-8. The determination of the sample size the energy of $\mathrm{X}$-ray beam are discussed on basis of the $\mathrm{X}$-ray linear attenuation coefficient (LAC) and the transmission rate of $\mathrm{Al}-\mathrm{TiB}_{2}$ and $\mathrm{Al}-\mathrm{SiC}$ system. The limitation of the charge coupled device (CCD) camera, such as spatial resolution and observing field, are taken into consideration as well. Phase retrieval method is applied to reduce the noises of tomographic images for Al-SiC system due to its poor contrast. The 3D particle clusters of $\mathrm{TiB}_{2}$ and $\mathrm{SiC}$ are reconstructed by self-developed program. The fractal dimension of $\mathrm{TiB}_{2}$ and $\mathrm{SiC}$ clusters are calculated around 2.7. The feasibility of observing alumina cluster in steel is discussed on basis of the latest capability of beamline BL20XU at Spring-8.
\end{abstract}

KEY WORDS: inclusion; steel; alumina; cluster; three-dimensional; X-ray; micro-CT.

\section{Introduction}

The inclusions in metal products largely decrease their mechanical properties. The fine inclusion particles coagulate each other in molten metal and grow up to clusters, which are much more harmful. It is an everlasting topic to remove inclusions as much as possible and control morphology of the remaining inclusions in metal products.

The three-dimensional (3D) structure of inclusion clusters plays a key role in the inclusion behaviors in molten metal. The 3D analysis of the inclusion cluster structure will provide significant information for understanding the mechanisms of inclusion behaviors in liquid metal, such as inclusion coagulation, flotation and bubble adhesion. Many modelling and experimental works ${ }^{1-5)}$ have been performed to investigate the inclusion behaviors by using spherical particles. Nevertheless, the morphology of the inclusions is far from spherical when they coagulate each other and grow up into clusters.

Fractal dimension ${ }^{6,7)}$ is one of the most important parameters describing the morphology of particle clusters, which specifies the relationship between the volume (area) and the size in length of a cluster. It is currently most common to observe of the inclusions on two-dimensional (2D) cross-

* Corresponding author: E-mail: litao0518@hotmail.com

DOI: http://dx.doi.org/10.2355/isijinternational.ISIJINT-2016-218 sections of a sample from metal products. An inclusion cluster appears as a few of isolated particles on a 2D crosssections of the samples. Tozawa et al. ${ }^{8)}$ firstly investigated the fractal dimension of alumina cluster in steel sample and its influence on floating velocity of clusters in liquid. The fractal dimension of an alumina cluster was calculated by 2D measurement of the cross-sections of a steel sample, which yielded a fractal dimension of 1.8. The model of cluster flotation velocity in liquid was modified using fractal dimension; it agreed well with the cold model experiments. Doo et $a l^{9}{ }^{9}$ investigated the fractal dimension of the alumina cluster extracted from steel according to the projected area of the cluster. The $2 \mathrm{D}$ fractal dimension was reported in the range of 1.80-1.95 with average of 1.88 .

However, those works above are all on basis on the observation on $2 \mathrm{D}$ cross section or projection area. It is very rare to find the experimental reports about $3 \mathrm{D}$ cluster structure analysis, especially the nonmetallic particle clusters in metal system because of its opaque and high melting point. X-ray Micro-CT is recently applied to observe the $3 \mathrm{D}$ pores and cracks in metal and polymer, ${ }^{10,11)}$ which is well known as nondestructive inspection method. ${ }^{12-15)}$ To achieve the 3D observation, the contrast of between the materials in the samples should be detectable, which is determined by the sample size, X-ray power and the types of materials. Mostly, the pores and crack in the solid have quite enough contrast of X-ray absorption rate to the solid material, particularly 
in polymers. It would be difficult to obtain an enough X-ray transmission rate for observation of metal samples. Hamilton et al. ${ }^{16)}$ made an effort to observe the $\mathrm{TiB}_{2}$ particles by X-ray micro-CT. However, the resolution is only $5 \mu \mathrm{m}$, which is not sufficient to derive quantitative description of the $3 \mathrm{D}$ morphology of the $\mathrm{TiB}_{2}$ particles.

A beamline of X-ray micro-CT is available in Spring-8, which is a large synchrotron radiation facility available in Japan. It yield a resolution of $0.5 \mu \mathrm{m}$, which is ten time higher than Hamilton's work. ${ }^{16)}$ The current authors' group has applied the X-ray micro-CT to study the 3D structure of $\mathrm{TiB}_{2}$ and $\mathrm{SiC}$ particle clusters in aluminium. ${ }^{17,18)}$ The coagulation of $\mathrm{SiC}$ particles in molten aluminum was studied based on the 3D observation of the particle clusters, ${ }^{5}$ which attracted quite a lot interests from researchers. In this study, we disclose the details of the development of the 3D observation method for $\mathrm{Al}-\mathrm{TiB}_{2}$ and $\mathrm{Al}-\mathrm{SiC}$ systems. The sample size and energy of X-ray source are determined by calculating the X-ray attenuation efficiencies and the transmission rate of the samples. This study opens an eye to observe and measure the morphology of inclusion clusters in metal product. The feasibility of observing alumina clusters in steel is discussed as well.

\section{Experimental}

The samples of aluminium with particle clusters were prepared in the mechanical agitating crucible, ${ }^{5,17,18)}$ which contains molten $\mathrm{Al}$ and particles $\left(\mathrm{TiB}_{2}\right.$ or $\left.\mathrm{SiC}\right)$. The molten aluminium with particles was stirred in a crucible at $973 \mathrm{~K}$ to prepare the particle clusters in aluminium. The size of the $\mathrm{TiB}_{2}$ particle varies from $2-30 \mu \mathrm{m}$ with peak diameter at 20 $\mu \mathrm{m}$. The volume fraction of the particle is around $0.5 \mathrm{vol} \%$. While the size of $\mathrm{SiC}$ particles is in the range of $2-30 \mu \mathrm{m}$ with peak diameter at $12 \mu \mathrm{m}$. The volume fraction of $\mathrm{SiC}$ is up to $2 \mathrm{vol} \%$. The samples were sucked from the molten aluminium by the silica tube with diameter of $3 \mathrm{~mm}$, and then processed by electron discharge machining to fit the requirement of the X-ray micro-CT.

Figure 1 shows the photo of the micro-CT in beamline BL20XU at Spring-8 and the processed sample. It is difficult to obtain a sample with diameter less than $0.5 \mathrm{~mm}$ by the electron discharge machining. On the other hand, the size of the charge coupled device (CCD) camera in the beamline

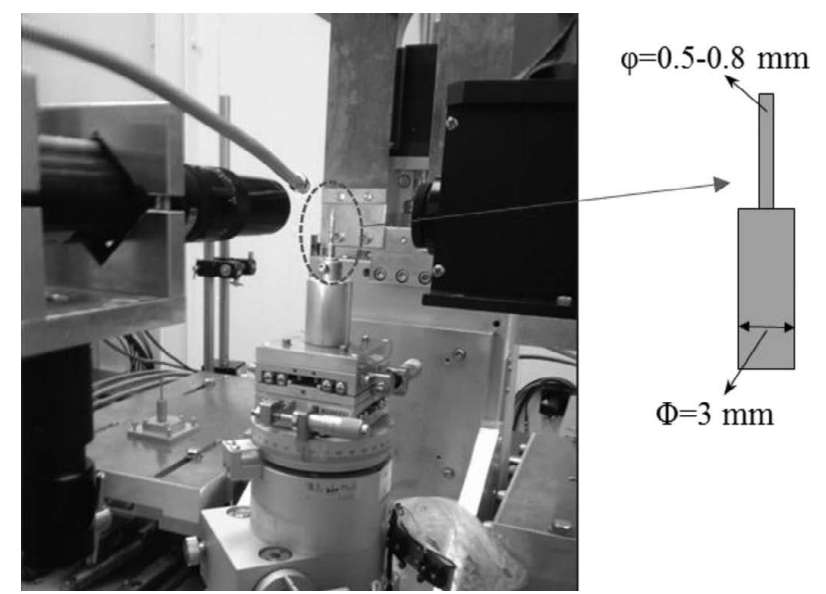

Fig. 1. Micro-CT in beamline BL20XU at Spring-8. of BL20XU is $0.95 \mathrm{~mm}$ in width and $0.7 \mathrm{~mm}$ in height. Therefore, the maximum diameter of the sample should be less than $0.95 \mathrm{~mm}$ in diameter. The sample size is set in the range of $0.5 \mathrm{~mm}-0.8 \mathrm{~mm}$ in this study; and the details of determining the sample size is discussed below.

\section{X-ray Tomography}

\subsection{BL20XU at Spring-8}

Spring- 8 is a large synchrotron radiation facility that delivers the most powerful synchrotron radiation available in Japan. The beamline BL20XU is designed to the imaging technologies, which is the second medium-length beamline in the Spring-8. Monochromator in beamline BL20XU is "Spring-8 standard" double crystal monochromator. The first crystal of monochromator is combination of Si (111) orientation crystal and $\mathrm{Si}$ (511) orientation. These two crystals are interchangeable by using linear-translation stage without venting the monochromator vacuum. The second crystal is Si 111-orientation. The energy region of X-ray beam was $8-37 \mathrm{keV}$ before and recently extended into $7.62-113 \mathrm{keV}$.

Figure 2 shows the principle of X-ray micro-CT. The parallel X-ray beam from source penetrates the sample and is partly absorbed by the sample; the charge-coupled device (CCD) camera detects the received energy of X-ray and generates projection images. The raw data for the sample are composted by multiple projections of the object being scanned. Tomographic reconstruction, essentially involves solving the inverse Radon transformation, ${ }^{19)}$ produces a series of cross-sectionsal images.

\subsection{X-ray Attenuation}

The contrast of the materials in the micro-CT images is determined by the X-ray linear attenuation rate of the different materials. The exponential attenuation law of a narrow beam of monoenergetic photons (X-ray) with an incident intensity $I_{0}$, penetrating a layer of sample is given by

$$
\frac{I}{I_{0}}=\exp \left[-\mu_{m} x\right]
$$

where, $I$ is the intensity of X-ray penetrating the sample, $x$ is the mass thickness of the sample and $\mu_{m}$ is the X-ray mass attenuation coefficient (MAC).

The X-ray MAC $\mu_{m}$ is expressed by the X-ray linear attenuation coefficient (LAC) $\mu_{l}$,

$$
\mu_{m}=\mu_{l} / \rho
$$

Where, $\rho$ is the density of material in the sample.

The mass thickness $x$ is defined as the mass per unit area,

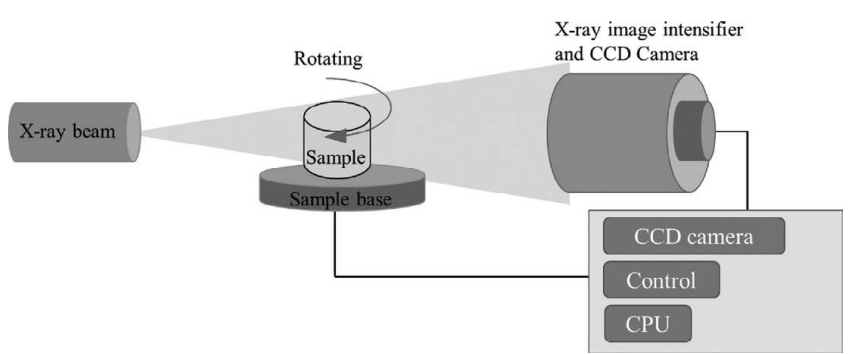

Fig. 2. Principle of X-ray micro-CT. 
which is obtained by product of the material density and the thickness $L$ in length,

$$
x=\rho L .
$$

By combining Eqs. (1)-(3), the X-ray transmission rate is given by

$$
\frac{I}{I_{0}}=\exp \left(-\mu_{l} L\right)
$$

The attenuation law mentioned above is based on the system including one type of materials. The X-ray contrast of two different materials is estimated by the relative difference in linear attenuation.

$$
\text { Difference }=\frac{\left|\mu_{l, 1}-\mu_{l, 2}\right|}{\mu_{l, 1}} .
$$

where, component-1 is dominated in the mixture. It is possible to distinguish the difference of materials when the relative difference in LAC exceeds $20 \%$.

The volume fraction of each material should be taken into account in a multiple materials system. The X-ray transmission rate of a multiple material is expressed by

$$
\frac{I}{I_{0}}=\exp \left[-\sum_{i}^{n} \varphi_{i} \mu_{l, i} L\right]
$$

where, $\varphi_{\underline{i}}$ is the volume fraction of the component $-i$.

To determine the size of samples and the energy of X-ray beam, the following criteria should be considered.

(1) Due to the small size of $\mathrm{TiB}_{2}$ and $\mathrm{SiC}$ particles, the spatial resolution of the CCD camera should be less than $1 \mu \mathrm{m}$. The maximum observing field then is $0.95 \mathrm{~mm}$ in width and $0.7 \mathrm{~mm}$ in height, which is limited by the CCD camera. Thus, the maximum diameter of the sample is set as $0.8 \mathrm{~mm}$ for safety.

(2) The X-ray energy available at BL20XU is between 8-37 keV when the sample of $\mathrm{Al}-\mathrm{TiB}_{2}$ and $\mathrm{Al}-\mathrm{SiC}$ were measured.

(3) The acceptable X-ray transmission rate is in the range is $0.2-0.8$, with optimist value around 0.5 .

(4) For the sake of involving more particle clusters in the sample, the sample volume should be as much as possible, on the premise of enough X-ray transmission rate and contrast in the $\mathrm{X}$-ray micro-CT images.

\subsection{Micro-CT Image Reconstruction}

The sample was settled between the X-ray source beam and the CCD camera. Numbers of projection images were taken by the CCD camera when the sample is rotating with a constant angular speed. In this study, totally 1891 projection images were taken for each sample of $\mathrm{Al}-\mathrm{TiB}_{2}$, in which the first 1-60 images are for background, 61-1 860 for the rotating samples (10 shots/degree), and 1 861-1 891 for background again. For the $\mathrm{Al}-\mathrm{SiC}$ system, the projection number was set as 3691 to deduce the noise, in which 1-60 are for background, 61-3 660 are the projections for samples, and 3 661-3 691 are for background again to confirm (180 degree, 20 shots/degree).

The projection images were then transferred into crosssectionsal images of the sample. The spatial resolution of the CCD camera is $0.5 \mu \mathrm{m}$. Totally, 1439 slices were obtained for each sample with the observed length of around $0.715 \mathrm{~mm}$, which is limited by the CCD camera. ImageJ was applied to process the 16 bit Micro-CT images, which is a public domain image processing software built up by the National Institutes of Health. A self-developed program developed on ImageJ to extract 3D clusters from the microCT image stacks, which was explained in detail in our previous work. ${ }^{17)}$

\section{Results and Discussions}

\subsection{Measurement of Aluminium Containing Particles}

The X-ray MAC is a function of the atomic number of the elements included in the materials. The atomic number of main elements in metal matrix and particles are listed in Table 1. The atomic numbers of $\mathrm{C}$ and $\mathrm{B}$ are quite closed. However, the $\mathrm{Si}$ in $\mathrm{SiC}$ is adjacent to $\mathrm{Al}$; while the $\mathrm{Ti}$ in $\mathrm{TiB}_{2}$ has large difference from $\mathrm{Al}$ in the atomic number that would lead to a much larger contrast between aluminium and $\mathrm{TiB}_{2}$.

Figure 3 shows the X-ray MAC of $\mathrm{Al}$ matrix and particles $\left(\mathrm{TiB}_{2}\right.$ and $\left.\mathrm{SiC}\right){ }^{20)}$ The gap between $\mathrm{Al}$ matrix and $\mathrm{TiB}_{2}$ particle in X-ray MAC is quite large; while the difference of that between $\mathrm{Al}$ matrix and $\mathrm{SiC}$ is very small, particularly with increasing energy of X-ray beam.

The X-ray transmission rate is a function of the LAC and the size of the sample. Figure 4 shows the X-ray LAC of Al matrix and $\mathrm{TiB}_{2}$ particles and their relative difference. The $\mathrm{X}$-ray LAC show the same tendency to the X-ray MAC. The difference of the LAC between $\mathrm{Al}$ and $\mathrm{TiB}_{2}$ is far greater than the criteria of $20 \%$ in the entire X-ray energy range of from $8 \mathrm{keV}$ up to $37 \mathrm{keV}$, though it decreases at $20 \mathrm{keV}$ of X-ray energy beam. Due to the large difference in LAC

Table 1. Atomic number of main elements in metal matrix and particles.

\begin{tabular}{ccccc}
\hline Material & $\begin{array}{c}\text { Density } \\
\left(\mathrm{g} / \mathrm{cm}^{3}\right)\end{array}$ & Element & $\begin{array}{c}\text { Atomic } \\
\text { Number }\end{array}$ & $\begin{array}{c}\text { Atomic } \\
\text { Weight }\end{array}$ \\
\hline Metal matrix & 2.7 & $\mathrm{Al}$ & 13 & 27 \\
\hline SiC particle & 3.21 & $\mathrm{Si}$ & 14 & 28 \\
\hline & $\mathrm{C}$ & 6 & 12 \\
$\mathrm{TiB}_{2}$ particle & 4.52 & $\mathrm{Ti}$ & 22 & 48 \\
& & $\mathrm{~B}$ & 5 & 11 \\
\hline
\end{tabular}

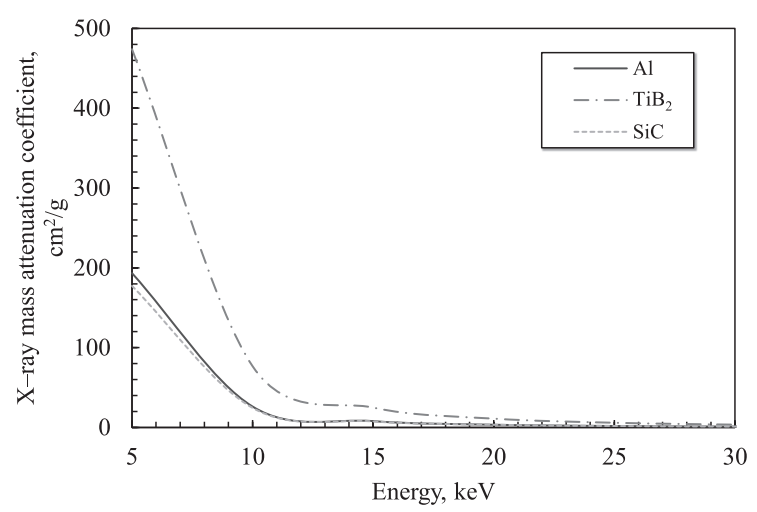

Fig. 3. X-ray MAC of $\mathrm{Al}$ matrix and particles ( $\mathrm{TiB}_{2}$ and $\left.\mathrm{SiC}\right)$. 


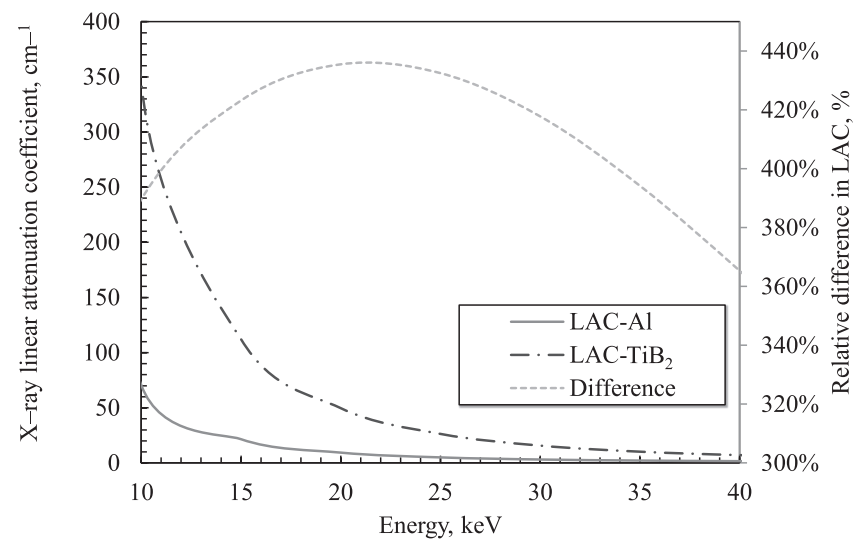

Fig. 4. X-ray $\mathrm{LAC}$ of $\mathrm{Al}$ matrix and $\mathrm{TiB}_{2}$ particles and their difference.

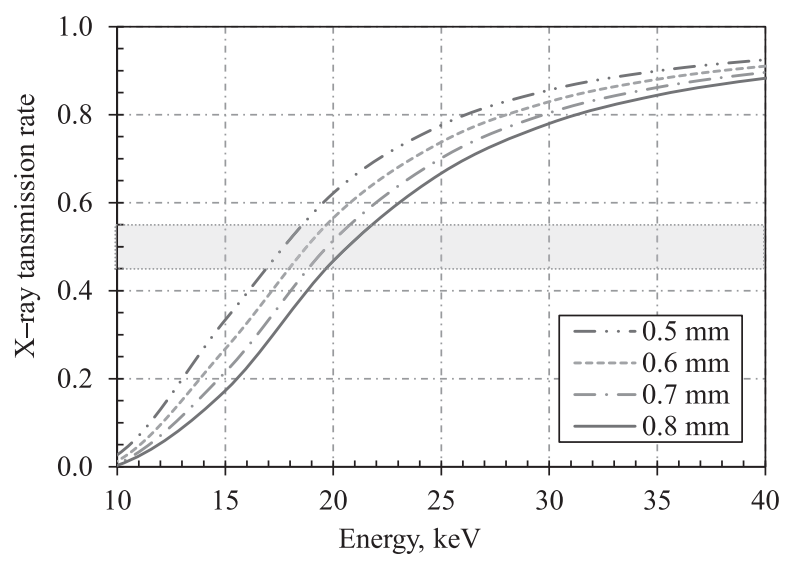

Fig. 5. X-ray transmission rate of $\mathrm{Al}-\mathrm{TiB}_{2}\left(0.5 \mathrm{vol} \% \mathrm{TiB}_{2}\right)$.

between $\mathrm{Al}$ and $\mathrm{TiB}_{2}$, the problem of contrast could be emitted from the consideration. The transmission rate is then the key factor on determining the energy of X-ray beam and the sample size of $\mathrm{Al}-\mathrm{TiB}_{2}$.

Figure 5 shows the X-ray transmission rate for $\mathrm{Al}-\mathrm{TiB}_{2}$, which is calculated by Eq. (6) with varying sample sizes. Since the volume fraction of $\mathrm{TiB}_{2}$ particles in the sample is very small, it has little effects on the $\mathrm{X}$-ray transmission rate. It is acceptable to observe the samples with an X-ray transmission rate of $0.2-0.8$, with optimized value at 0.5 for the observation. In order to increase the particle clusters containing in the observed sample, the sample size is determined at the maximum $(0.8 \mathrm{~mm})$, which is limited by the CCD camera. The energy of X-ray beam is around $20 \mathrm{keV}$ to achieve the transmission rate of 0.5 ; and was finally fixed at $19.99 \mathrm{keV}$ after testing the quality of the $\mathrm{X}$-ray images.

Figure 6 shows the change of LAC of $\mathrm{Al}$ and $\mathrm{SiC}$ with $\mathrm{X}$-ray energy. It is obvious that the difference in LAC between $\mathrm{Al}$ and $\mathrm{SiC}$ is much smaller than that between $\mathrm{Al}$ and $\mathrm{TiB}_{2}$. The SiC particles may be difficult to be distinguished by the CCD camera in the X-ray micro-CT images. Figure 7 shows the X-ray transmission rate of $\mathrm{Al}-\mathrm{SiC}$ containing $2 \mathrm{vol} \%$ particles. The X-ray transmission rate of the sample with certain size increases with the increasing energy of X-ray beam; whereas it decreases with the increasing size of samples exposed under the X-ray with the same energy. It turns out that, on basis of Fig. 6 , the

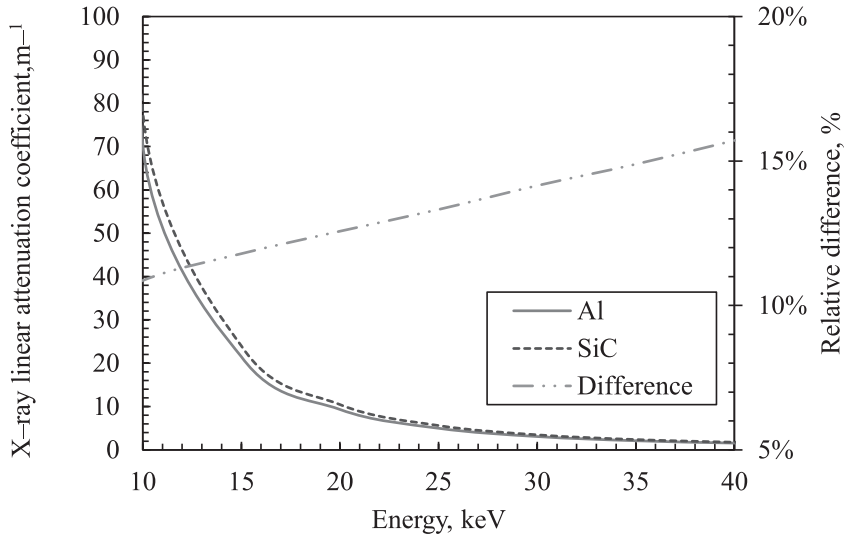

Fig. 6. X-ray LAC of Al matrix and SiC particles and their difference.

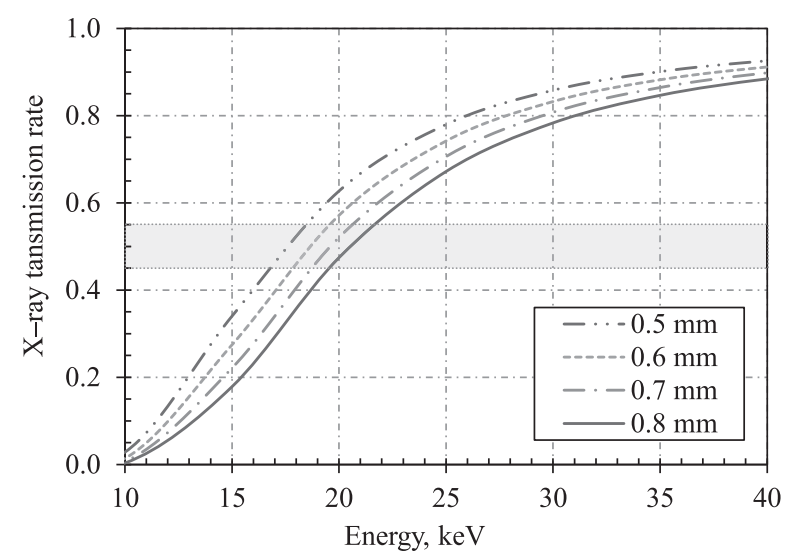

Fig. 7. X-ray transmission rate of $\mathrm{Al}-\mathrm{SiC}(2 \mathrm{vol} \% \mathrm{SiC})$.

contrast between $\mathrm{Al}$ and $\mathrm{SiC}$ increases with X-ray energy. On the other hand, it is required to adjust the X-ray transmission rate to be around 0.5 in order to achieve the best contrast of micro-CT image. When the sample size is set at $0.8 \mathrm{~mm}$ in diameter, the energy of X-ray beam should be around $21 \mathrm{keV}$ according to Fig. 7. However, the thicker the sample, the more noise comes from photon scattering, which would practically decrease the contrast. In this way, a thinner sample should be used for $\mathrm{Al}-\mathrm{SiC}$ system. The sample size of Al-SiC is set at $0.5 \mathrm{~mm}$ in diameter and the energy of the X-ray source is set as $18 \mathrm{keV}$ to obtain an $\mathrm{X}$-ray transmission rate of 0.50 .

\subsection{D Reconstruction of Particle Clusters in Alumin- ium}

An example of 8-bit micro-CT cross-sectional image of Al-TiB 2 sample is show in Fig. 8(a). The white area is $\mathrm{TiB}_{2}$ particles; the grey area is Al matrix; and the black area is the background of air. It turns out that the contrast between $\mathrm{Al}$ and $\mathrm{TiB}_{2}$ is quite large. Figure 8(b) shows the binary image preprocessed image by setting a threshold of grey value in Image J.

The particle clusters in the samples are reconstructed from the series of cross-sectional images by a self-developed program based on ImageJ. Figure 9 shows an example of $\mathrm{TiB}_{2}$ clusters and its cross-sectional slices. It is obviously difficult to identify the cluster when one of the slices 


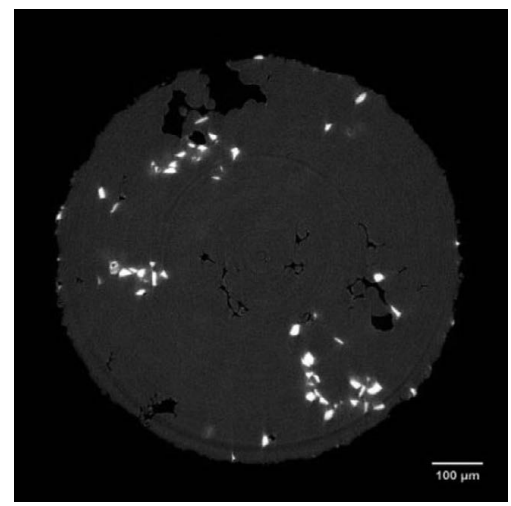

(a). 8-bit image from X-ray Micro-CT.

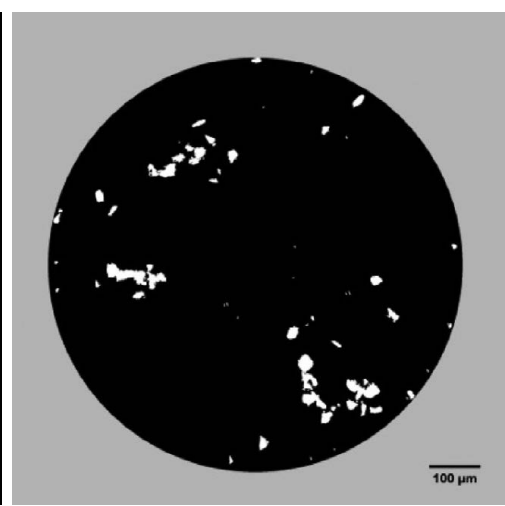

(b). Processed image by ImageJ.

Fig. 8. Cross-sectional image from X-ray Micro-CT and processed image.

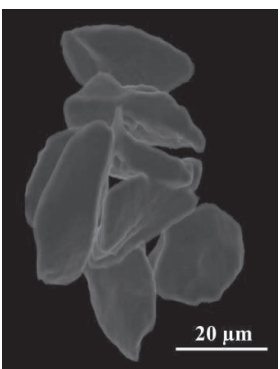

(a). 3D cluster.

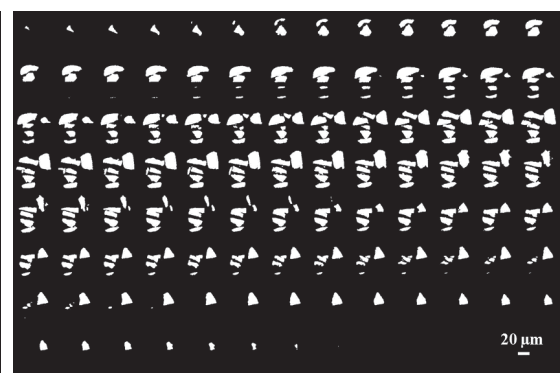

(b). Slices of an extracted cluster.
Fig. 9. Example of $\mathrm{TiB}_{2}$ cluster and its cross sectional slices.

appears independently. The fractal dimension of the cluster is 2.74 , which is calculated by

$$
V=\frac{\pi}{6} d_{\text {ave }}^{D_{f}}
$$

where, the $V$ is the volume of the cluster; $d_{\text {ave }}$ is the average diameter of the cluster in $x, y$ and $z$ direction; $D_{f}$ is the fractal dimension.

When it comes to the Al-SiC system, the contrast of the $\mathrm{X}$-ray micro-CT images becomes poor. Figure 10(a) shows an 8-bit micro-CT image of $\mathrm{Al}-\mathrm{SiC}$ sample. A magnified area is shown in Fig. 10(b) where the fine dots in the $\mathrm{Al}$ matrix have the similar grey values as the $\mathrm{SiC}$ particles. It is difficult to identify the $\mathrm{SiC}$ particle from the $\mathrm{Al}$ matrix e by setting a threshold of grey value, as done for $\mathrm{Al}-\mathrm{TiB}_{2}$.

The quality of the tomographic images were largely improved by applying the phase retrieval methods ${ }^{21-23)}$ implemented by Transport-of-Intensity equation ${ }^{22}$ using fast Fourier transform (FFT) method. ${ }^{23)}$ The phase-retrieval method was developed to obtain the projected phase and absorption information of the object in multi-material objects with distinct complex refractive indexes. The algorithm was implemented using phase contrast data acquired at the Spring-8 Synchrotron facility in Japan. The 3D complex refractive index distribution of a multi-material test object was quantitatively reconstructed using a single $\mathrm{X}$-ray phase contrast image per projection. The technique is robust in the presence of noise, compared to conventional absorption based tomography. Figure 11(a) shows a normalized X-ray micro-CT image of Al-SiC obtained by the

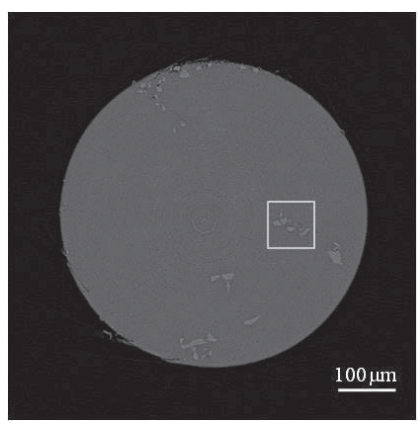

(a). X-ray micro-CT image

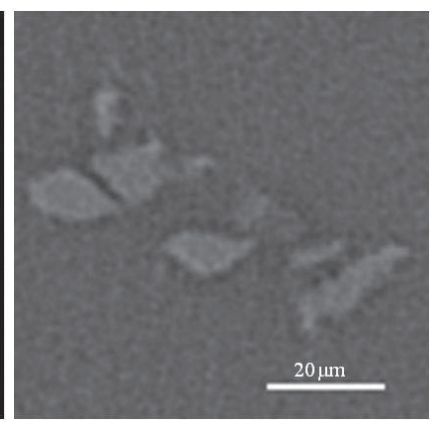

(b). Magnified view
Fig. 10. X-ray micro-CT image obtained by ordinary reconstruction method.

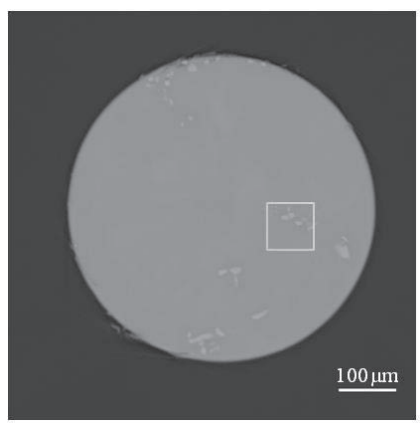

(a). Phase retrieval image of $\mathrm{Al}-\mathrm{SiC}$

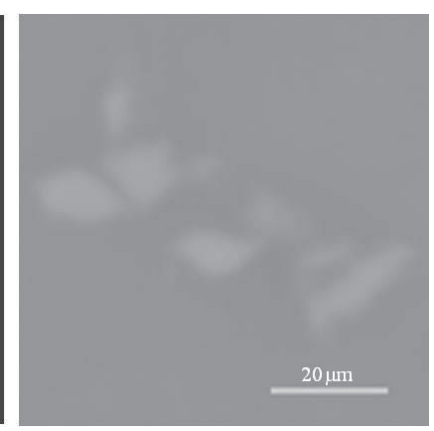

(b). Magnified view
Fig. 11. Normalized X-ray micro-CT image obtained by phase retrieval.

phase retrieval based on FFT algorithm. As seen from Fig. 11(b), the noise of dots shown in Fig. 10 has been largely removed. The phase retrieval images are then and converted into 8-bit images; and a threshold is set to convert the images into binary, which are shown in Fig. 12. Figure 13 gives an example of $\mathrm{SiC}$ cluster whose fractal dimension is 2.7 calculated by Eq. (7). It shows a similar contracture as $\mathrm{TiB}_{2}$ clusters. On basis of statistical analysis of thousands of $\mathrm{TiB}_{2}{ }^{17)}$ and $\mathrm{SiC}^{5)}$ clusters, it turned out that their fractal dimension is around 2.7. The fractal dimension of the $2 \mathrm{D}$ cross-sectional particles is around 1.8, which agreed well with Tozawa's work for alumina cluster in steel. ${ }^{8)}$ 


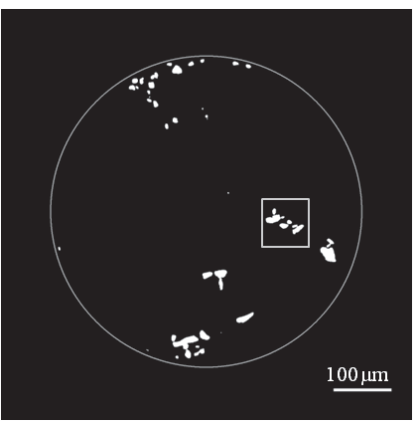

(a). Binary image

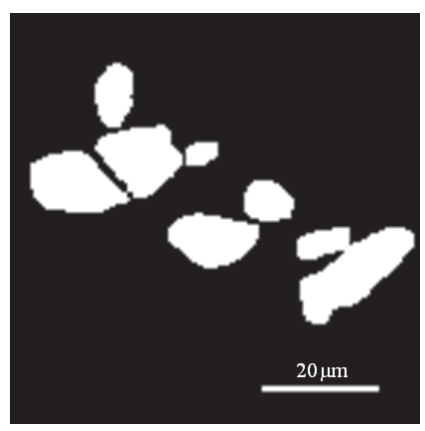

(b). Magnified view
Fig. 12. X-ray micro-CT images processed by ImageJ.

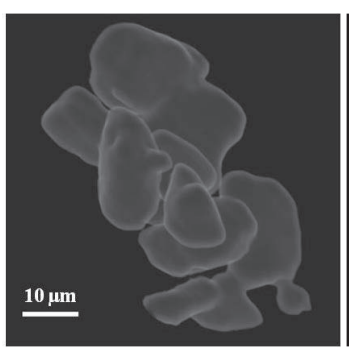

(a). $3 \mathrm{D}$ cluster

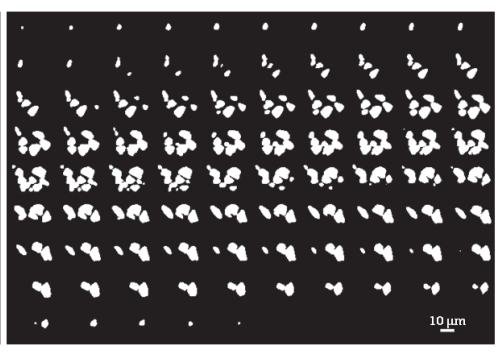

(b). Slices of an extracted cluster
Fig. 13. Example of $\mathrm{SiC}$ cluster and its cross sectional slices.

\subsection{Alumina Cluster in Steel}

The atomic number of $\mathrm{Fe}$ (26) is much larger than that of $\mathrm{Al}$; thus it would be much difficult for the X-ray to penetrate the steel sample. It thus requires a much higher energy of X-ray to observe the steel sample than that for aluminium samples. Figure 14 shows the LAC of Fe and $\mathrm{Al}_{2} \mathrm{O}_{3}$ and their relative difference. An energy absorption edge $^{25)}$ appears at $9 \mathrm{keV}$ for $\mathrm{Fe}$, due to the photoelectric effect, which is caused by the removing of electrons from the shells around the nuclear in the atoms. It is common to set the energy of X-ray beam around the absorption edge, which results in the maximum contrast of the micro-CT image. However, the X-ray transmission rate of the sample is another critical factor of observation. Figure 15 shows the $\mathrm{X}$-ray transmission rate for $\mathrm{Fe}-\mathrm{Al}_{2} \mathrm{O}_{3}$ samples containing 1 vol $\% \mathrm{Al}_{2} \mathrm{O}_{3}$. The volume fraction is calculated by assuming that all the inclusions in the steel sample $(\mathrm{T}[\mathrm{O}]=20 \mathrm{ppm})$ appearing in term of $\mathrm{Al}_{2} \mathrm{O}_{3}$. The X-ray transmission rate is extremely small with photon energy of $9 \mathrm{keV}$, though the contrast between $\mathrm{Fe}$ and $\mathrm{Al}_{2} \mathrm{O}_{3}$ is large. Actually, the minimum X-ray energy is around $30 \mathrm{keV}$ even for observing a sample with diameter of $200 \mu \mathrm{m}$. Figure 16 shows an alumina cluster extracted from a steel sample. ${ }^{9)}$ The size of alumina clusters reaches several tens microns, even a hundred microns. Therefore, it is difficult to guarantee that alumina clusters are involved in a sample with diameter of $0.2 \mathrm{~mm}$. Fortunately, the energy range of X-ray up to 113 $\mathrm{keV}$ is currently available at beamline BL20XU at Spring-8, which makes it possible to observer $\mathrm{Fe}-\mathrm{Al}_{2} \mathrm{O}_{3}$ samples with larger size. On the other hand, the spatial resolution should be less than $1 \mu \mathrm{m}$ due to the small size of alumina particles contained in the cluster. We set the maximum diameter of the sample at $0.8 \mathrm{~mm}$ as before due to the limitation of the

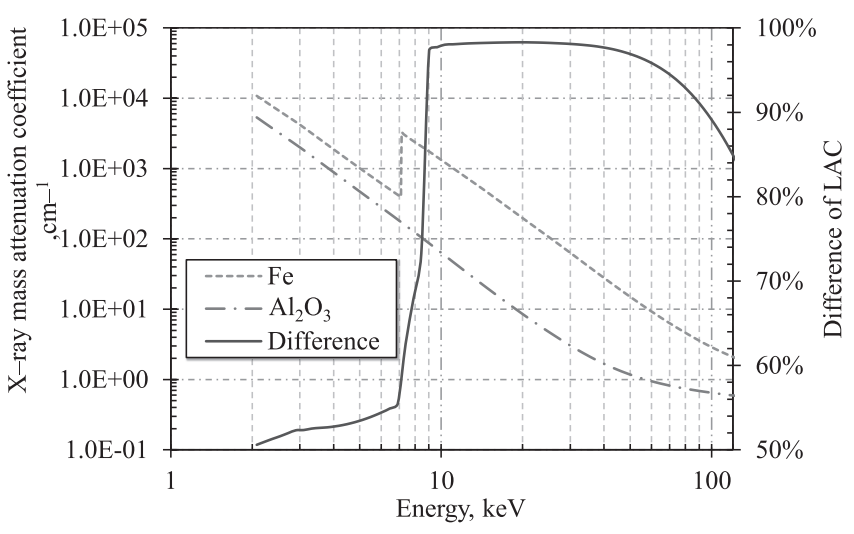

Fig. 14. X-ray $\mathrm{LAC}$ of $\mathrm{Fe}$ and $\mathrm{Al}_{2} \mathrm{O}_{3}$ particles and their relative difference.

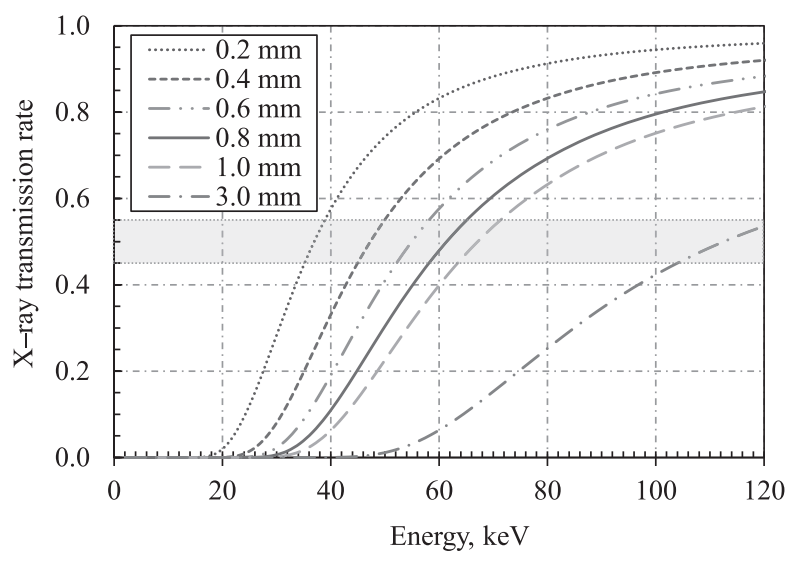

Fig. 15. $\mathrm{X}$-ray transmission rate of $\mathrm{Fe}-\mathrm{Al}_{2} \mathrm{O}_{3}\left(1 \mathrm{vol} \% \mathrm{Al}_{2} \mathrm{O}_{3}\right)$.

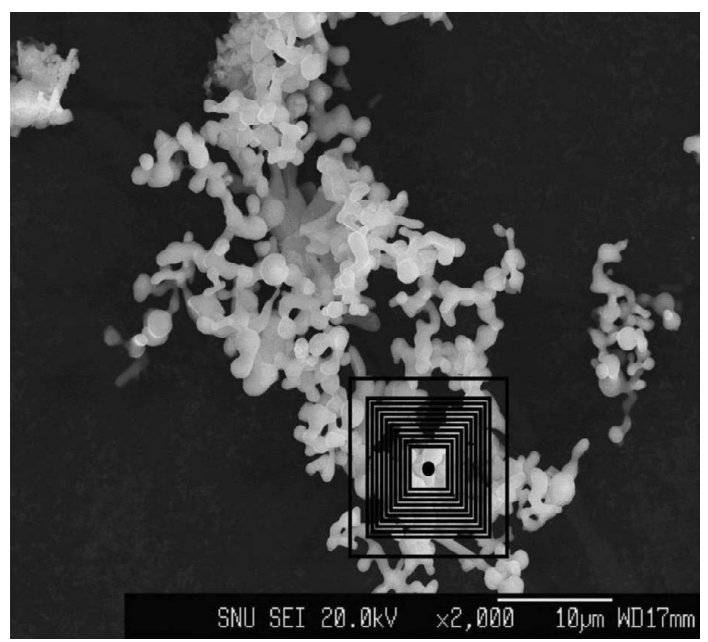

Fig. 16. Alumina extracted from steel sample.

observing field of the CCD camera. Therefore, the energy of X-ray beam should be around $60 \mathrm{keV}$ for to achieve an $\mathrm{X}$-ray transmission rate around 0.5 . The measurable sample size would theoretically reach to $3 \mathrm{~mm}$ if a CCD camera with enough spatial resolution is available.

Though the behavior of alumina inclusions has been attracting much interest, the other types of inclusion have bad influence to the steel products as well. The feasibility of $3 \mathrm{D}$ observation of other inclusion would be considered in the future. The contrast is low when the elements in the inclusions have similar atomic number to $\mathrm{Fe}$, such as $\mathrm{FeO}$, 
$\mathrm{MnO}$, and MnS. The phase retrieval method would then be applied as done for $\mathrm{Al}-\mathrm{SiC}$ system.

\section{Conclusions}

In this study, the method of observing 3D inclusion clusters in metal was disclosed in details. The Al-TiB2 and $\mathrm{Al}-\mathrm{SiC}$ system were measured by the X-ray micro-CT available at Spring-8. The 3D reconstruction of the X-ray micro-CT images was presented, with the calculation of the fractal dimension. The feasibility of observing alumina cluster in steel is discussed on basis of the latest capability of beamline BL20Xu at Spring-8.

(1) The contrast of $\mathrm{Al}-\mathrm{TiB}_{2}$ system is sufficiently large that it does not effect on determining the sample size. The sample size is then limited by the observing field of the CCD camera. The energy of X-ray beam is set at $19.99 \mathrm{keV}$ to achieve an X-ray transmission rate of 0.55 .

(2) The difference in $\mathrm{LAC}$ between $\mathrm{Al}$ and $\mathrm{SiC}$ is pretty close that the contrast on the micro-CT images is bad. In order to reduce the noise coming from photon scattering, the sample size is set to be the minimum $(0.5 \mathrm{~mm})$ processable by electron discharge machining. And the energy of X-ray beam is set at $18 \mathrm{keV}$ to achieve an $\mathrm{X}$-ray transmission rate of 0.50 .

(3) The X-ray micro-CT images of $\mathrm{Al}-\mathrm{TiB}_{2}$ is easier to be processed due to its large contrast; while the phase retrieval method is applied to the tomographic images of $\mathrm{Al}-\mathrm{SiC}$ to reduce the noises. The fractal dimension of both $\mathrm{TiB}_{2}$ and $\mathrm{SiC}$ clusters in aluminium is around 2.7.

(4) The alumina clusters in steel is theoretically able to be observed currently due to the larger range of X-ray energy available in beamline BL20XU at Spring-8. The sample should be processed into cylinder with diameter around $0.8 \mathrm{~mm}$. The energy of X-ray should be around 60 $\mathrm{keV}$.

\section{Acknowledgement}

This work was partly supported by Grant-in-Aid for Scientific Research (A) (No. 22246097) which is provided by Japan Society for the Promotion of Science (JSPS). Project numbers of Spring-8 are 2011B1395 and 2012B1448 on beamline BL20XU. The authors wish to express thanks to Dr. A. Takeuchi and Dr. Y. Suzuki for their help during the operation of the X-ray micro-CT at Spring-8. We also thanks Dr. M. Iguchi of Nihon Ceratec Co., Ltd. for the cooperation on preparing the $\mathrm{Al}-\mathrm{TiB}_{2}$ metal matrix composite.

\section{REFERENCES}

1) H. Arai, K. Matsumoto, S. Shimasaki and S. Taniguchi: ISIJ Int., 49 (2009), 965

2) T. Nakaoka, K. Matsumoto, H. Arai, S. Shimasaki and S. Taniguchi: Prog. Comput. Fluid Dyn., 10 (2010), 62.

3) T. Li, R. Oka, S. Taniguchi and S. Shimasaki: CAMP-ISIJ, 24 (2011), 811.

4) T. Li, S. Shimasaki, S. Taniguchi and K. Uesugi: 13th Int. Conf. Aluminum Alloys, TMS, Warrendale, PA, (2012), 1337.

5) T. Li, S. Shimasaki, S. Taniguchi, S. Narita and K. Uesugi: ISIJ Int., 53 (2013), 1958

6) K. Falconer: Fractal Geometry, Wiley, New York, (2003), 308.

7) H. Sagan: Space-Filling Curves, Springer-Verlag, Berlin, (1994), 156.

8) H. Tozawa, Y. Kato, K. Sorimachi and T. Nakanishi: ISIJ Int., 39 (1999), 426.

9) W. C. Doo, D. Y. Kim, S. C. Kang and K. W. Yi: ISIJ Int., 47 (2007), 1070.

10) J. Y. Buffiere, E. Maire, Cloetens, G. Lormand and R. Fourgeres: Acta Mater., 47 (1999), 1613.

11) A. Elmoutaouakkil, G. Fuchs, Bergounhon, R. Peres and F. Peyrin: J. Phys. D: Appl. Phys., 36 (2003), A37.

12) R. Jullien, M. Kolb and R. Rotet: J. Phys. Lett., 45 (1984), 211.

13) T. A. Witten and L. M. Sander: Phys. Rev. Lett., 47 (1981), 1400.

14) P. Meakin: Phys. Rev. A, 27 (1983), 604.

15) P. Meakin and H. E. Stanley: Phys. Rev. Lett., 51 (1983), 1457.

16) R. W. Hamilton, M. F. Forste, R. J. Dashwood and D. Lee: Scr. Mater., 46 (2002), 25.

17) T. Li, S. Shimasaki, S. Taniguchi, S. Narita and K. Uesugi: ISIJ Int., 53 (2013), 1943

18) T. Li, S. Shimasaki, S. Taniguchi, K. Uesugi and S. Narita: Metall. Mater. Trans. B, 44 (2013), 750.

19) S. R. Deans: The Radon Transform and Some of Its Applications, John Wiley \& Sons, New York, (1983).

20) NIST: XAAMDI, X-ray Attenuation and Absorption for Materials of Dosimetric Interest Database, NIST, Gaithersburg, MD, (2013).

21) T. E. Gureyev and K. A. Nugent: Opt. Commun., 133 (1997), 339.

22) D. Paganin and K. A. Nugent: Phys. Rev. Lett., 80 (1998), 2586.

23) M. A. Beltran, D. M. Paganin, K. Uesugi and M. J. Kitchen: Opt. Express, 18 (2010), 6423.

24) Duhamel and M. Vetterli: IEEE Signal Proc. Soc., 19 (1990), 259.

25) J. W. Robinson, E. M. Skelly Frame and G. M. Frame, II: Undergraduate Instrumental Analysis, Ed. 6, Marcel Dekker, New York, (2005), 543. 